\title{
A Study on Relationships among Conflict Management and School Effectiveness
}

\author{
Mei-Chen Kuo ${ }^{1}$, Fu-Yu Lin*², Chin-Yen Lin ${ }^{3}$, Farn-Shing Chen ${ }^{4}$ \\ ${ }^{1}$ The Affiliated Taichung Agricultural Senior High School Of National Chung Hsing University, Taiwan, ROC \\ ${ }^{2}$ National Changhua University of Education, Taiwan, ROC \\ ${ }^{3}$ National Taipei University of Technology, Taiwan, ROC \\ ${ }^{4}$ Chienkuo Technology University, Taiwan, ROC \\ *lfy66208@yahoo.com.tw
}

\begin{abstract}
The aim of this study was to verify the relationships among principals' conflict management and school effectiveness from administrative heads' viewpoints at public vocational schools in Taiwan. This study employed questionnaire survey method to collect the research data. The descriptive statistics, stepwise multiple regression analysis, Pearson correlation were used for data analysis. According to the empirical data analysis, the major findings of this study are as follows: 1.Using cooperation and compromising methods can successfully increase school effectiveness. 2. The most preferred conflict management chosen by the principals are cooperation and compromising methods. 3. It is efficient to predict school effectiveness in the three dimensions of the conflict management of cooperation, escape, and compliance.
\end{abstract}

Index Terms -Leadership, Conflict management, Effectiveness

\section{Introduction}

Secondary Education is a crucial point which combines compulsory education and higher education. It also plays an important role in educational system of each country. United Stated Office of Education issued Investing in America's future: A blueprint for transforming career and technical education in 2012 and organized US $\$ 1,400$ million to promote the Car Perkins career and Technical Education Act to accomplish the development of technical and vocational education and to cope with the changes of diversify industry in the future and the needs of exchange the positions of jobs.

To face the change of the diversify society, the current principles of vocational schools must not only achieve the target of technical and vocational education which Ministry of Education set, but also satisfy parents' expectations of children's entrance to the next grade schools. This situation requires more imperceptibly to each office. Therefore, the mode of leadership in senior vocational schools turned into interpersonal relationship from rationality, and then became the mode of adaptability in tactics.

In the process of the principals in senior vocational schools, "conflict" is existed with the system. Thus, when it happens in campus, it will test the principals in senior vocational schools how to lead the school toward excellent and to do a good conflict management at the same time.

\section{Motivation of the Study}

Domestic and foreign scholars researched that the conflict has high correlation with the school effectiveness. They stated that the effective conflict management increases the adaption of individuals and groups and the achievements of organizations. Most of these kinds of the studies used the variable about administrator's communicative behaviours, the strategies of authority operation, or organizational operation, organizational cultures, etc. Hence, according the results of these studies involved the principals' leadership; conflict management exactly influenced the school effectiveness in elementary and junior high schools. However, it is worthy to explore whether if the principal's in senior vocational schools used the conflict management impact the school effectiveness or not.

There are many studies which definitely positive way of conflict discussing the conflict management. Besides, the conflict helps solve problems and becomes the development of essential power [3]. Tjosvold and some researchers pointed out that if the person could manage conflict actively while facing the conflict management, he/she would benefit a great deal. So, if the conflict management could be applied appropriately in the administration of senior vocational schools, each office would communicate better. In addition, the workers will express their own opinions bravely and the quality of administration will also be improved. Then, the promotion of creation and innovation of senior vocational schools reach positive significance.

In the high technological society of 21 st century, various systems became mature that made the whole society toward multielement. The administrators have more and more pressure and challenge. Therefore, they unavoidably feel anxious, nervous, and frustrated. The nearly studies claimed that the administrators gain the stress mainly from frequent requirement of workshops, regulation of educational evaluations, human interactions, and new policies promoted by new supervisor [5].

Management and resolution of conflict are the most important ability of principals. Because the principals ask the administrators, heads and teachers for higher standard and more complex distribution, the conflict appears. When it happens, as a senior vocational principal has to know how to manipulate the conflict management, to make it transform into the positive power, and to reinforce own educational ideal [4]. How do the senior vocational principals guide the colleagues enhance the performance of achievements and how to mastery 
and manipulate appropriately the skills of conflict management? Those became important issues which are not to be ignored.

\section{Theoretical Background}

\subsection{Conflict Management}

According to the history, since the human beings' beginning of living in a group, the conflict was existed and was in a conflict situation. UESCO (United Nations Educational, Scientific and Cultural Organization) treated "Armed conflict" as an obstacle of achieving the universal education in EFA Global Monitoring Report in 2011 [15]. Consequently, the reactions between people and groups of all organizations cause the conflict and people would probably have contrasting concepts or ideas because of different targets or the cognition of value. Rahim(2010) indicated that it is the natural outcomes of reciprocal influences between humans [10]. The conflict occurs and the relationships among people and organizations becomes unendurable when two or more people hope to have some sources but the supply cannot meet the demand, when people do not identify the behaviours or actions to each other, or when people have different attitudes, values, beliefs, skills.

Most of the scholars thought that the conflict is discriminated in three types, "the relationship between conflicts, the relationship between tasks, and the relationship between procedures" [2][8][13]. Pondy discovered that the conflict is not a series of independent events but a set of relative events. It means that all conflicts are the parts of whole process. The current conflict is indeed the continuity of the last conflict [9]. Pondy also divided the conflict into five stages: latent, perceived, felt, manifest, and aftermath. Robbins proposed the mode of four stages in organizations which clearly elaborated the form of conflict: (1) potential opposition; (2) cognition and personalization; (3) behavior; (4) outcomes [11].

Based on the organization conflict might cause the results of constructive and destructiveness, it is more important to rule effectively than solving the conflict. The administrators have to ensure the work efficiency and creative in organizations to make these two main points keep in balance. Thus, they must use various ways to manage conflicts effectively and increase more constructive of conflict, but decrease the destructiveness of conflict [11]. Broadly speaking, the conflict means the different steps of processing including competition, cooperation, escape, compliance, and compromising.

In early period, the studies of conflict management are based on Blake and Mouton's researches. They developed two-surface theory of conflict management of which three hypotheses are (1) the attention from all people; (2) the attention of production; (3) the organizations of trying to solve problems. And then the theory forms five styles of conflict management: problem solving, withdrawing, compromising, smoothing, and forcing. Lawerence and Lorsh defined these five styles as confrontation, compromising, smoothing, forcing, and withdrawing referred to Blake and Mouton's study. Thomas got a step further of Blake and Mouton's twosurface theory [12]. According to it, he established the conflict management on "assertiveness" and "cooperation". "Assertiveness" emphasized on satisfying oneself, and "cooperation" stressed on satisfying others. Thomas expanded this theory which composed five modes of conflict management.

The conflicts in schools include the conflict between teachers and students, the conflict between teachers, the conflict between teachers and parents. The positive or negative effects of the conflict to the school effectiveness depend on the characters. However, people cannot ignore more than half conflicts which possibly influence the operations of school administrations and teaching businesses even ruin the interpersonal relationship. For this reason, it would violate the principles of fairness and justice and block the way of communication, then causing misunderstanding and dissatisfied. As the problems occur, the heads of the school should find the way to solve the problems, manage the problems, and lead into the conflict properly.

\subsection{School Effectiveness}

The studies of school effectiveness were traceable in history and were affected by the background of the environment at that time. Schools are non-profit organizations which are unlike the general enterprises that judge the effectiveness of production, benefit, employment stability, and job satisfaction of employees. School effectiveness possess the multielement of which way to determine is to create better school cultures between members, behaviour norms, the value of developing the organizations, and responsibility. It is uneasy to determine the factors and usually use a series scientific and sensible investigation to inquire [7].

Most of the researchers of educational administration analyse in achievement of organizations' targets and satisfaction of members' needs. Besides, they also stand on school characters to list the index of effectiveness for measurement. In addition to accept the professional evaluation of measuring methods, it is more important that the awareness of school effectiveness to school members. It also evaluates from students' acquisition, teachers' instruction, heads' leading and management, and parents' and local personalities' participation to know the school effectiveness detailed [1][6][14]. As above mentioned, it is not objective to get the school effectiveness, but is subjective to find the answers. In other words, it is the feel and viewpoint of school effectiveness in psychology. Therefore, it is reasonable to infer the principals have empathy in the same influence of psychology.

\section{Instruments and Data Analysis}

\subsection{Instruments}

After finishing the first draft of this instrument, the public and private senior vocational schools principals and directors were invited to revise the questions. Next, the savants assisted to put the aims at the relevance, content, diction, scoring, and arrangement of questionnaires to modify. Besides, they also correct and analyse term by term. 
According to the instrument of this study, the results for measuring scale of conflict management showed acceptable fit for the overall model in absolute terms ( $\chi 2$ 2 $=664.56$, $\mathrm{df}=358(* * * \mathrm{p}<.001), \mathrm{CFI}=.92$, RMSEA $=.07$, AGFI $=.746$, $\mathrm{GFI}=.78$ ). Those four indexes of collocation degree reached the standard (CFI=.90) and the item-factor loadings were close to the significant level $(t=.01)$. It means that 'measuring scale of conflict management' of each converge validity were in the acceptable range. According to the results for 'measuring scale of school effectiveness' also showed acceptable fit ( $\chi$ $2=252.50, \mathrm{df}=138(* * * \mathrm{p}<.001), \quad \mathrm{CFI}=.96, \quad \mathrm{RMSEA}=.07$, $\mathrm{AGFI}=.81, \mathrm{GFI}=.86$ ). Those four indexes of collocation degree reached the standard (CFI=.90, GFI=.09) and the itemfactor were close to the significant level $(t=.01)$. It showed a significant in each converge validity of school effectiveness.

\subsection{Data Analysis}

Stratified random sampling was selected in this study. The background information of respondents was in Table 1.

Table 1 Analysis of Background Information

\begin{tabular}{|c|c|c|c|}
\hline Variable & Item & Population & Percentage (\%) \\
\hline \multirow{4}{*}{ School Position } & Director & 101 & 30.9 \\
\cline { 2 - 4 } & $\begin{array}{c}\text { Director of } \\
\text { Department }\end{array}$ & 103 & 31.5 \\
\cline { 2 - 4 } & Group Leader & 123 & 37.6 \\
\hline \multirow{3}{*}{ Sex } & Male & 200 & 61.3 \\
\cline { 2 - 4 } & Femal & 127 & 38.7 \\
\hline \multirow{3}{*}{$\begin{array}{c}\text { Administrators' } \\
\text { Seniority }\end{array}$} & Under 5 years & 162 & 49.5 \\
\cline { 2 - 4 } & 6 to 10 years & 77 & 23.5 \\
\cline { 2 - 4 } & 11 to 15 years & 47 & 14.4 \\
\cline { 2 - 4 } & Over 16 years & 41 & 12.6 \\
\hline \multicolumn{2}{|c|}{$\mathrm{N}=327$} \\
\hline
\end{tabular}

In order to explore the administrator's viewpoints to the usage of conflict management by principals, we used statistics of every mean and standard deviation to get the information about each answer and to understand the usage of conflict strategies by principals. As Table 2 is analysis of dimensionality.

Table 2 Mean and Standard Deviation in Conflict Management

\begin{tabular}{|c|c|c|c|}
\hline Dimensionality & $\begin{array}{c}\text { Number of } \\
\text { questions }\end{array}$ & Mean & $\begin{array}{c}\text { Standard } \\
\text { Deviation }\end{array}$ \\
\hline Competition & 6 & 2.89 & .659 \\
\hline Cooperation & 6 & 3.78 & .646 \\
\hline Compliance & 6 & 3.78 & .646 \\
\hline Escape & 5 & 2.74 & .641 \\
\hline Compromising & 6 & 3.55 & .531 \\
\hline
\end{tabular}

Each dimensionality of mean in 'conflict management' was within 2.74 to 3.78 . As shown, senior vocational heads thought when the conflict occurred, the principals often adopted the way 'cooperation', rather than applying pressure or showing no interest in it. The principals always listened attentively and communicated with workers.

In order to explore the administrative heads' viewpoints of school effectiveness, we used statistics of every mean and standard deviation to get the information about each answer and to understand the administrative heads' viewpoints of school effectiveness. As Table 3 is analysis of dimensionality.

Table 3 Mean and Standard Deviation in School Effectiveness

\begin{tabular}{|l|c|c|c|}
\hline Dimensionality & $\begin{array}{c}\text { Number of } \\
\text { questions }\end{array}$ & Mean & $\begin{array}{c}\text { Standard } \\
\text { Deviation }\end{array}$ \\
\hline Students' Acquisition & 4 & 3.33 & .703 \\
\hline Teachers' Instruction & 5 & 3.66 & .493 \\
\hline Administration & 5 & 3.71 & .666 \\
\hline Community Relations & 5 & 3.80 & .543 \\
\hline Total & 19 & 3.64 & .478 \\
\hline
\end{tabular}

Each dimensionality of mean in school effectiveness was within 3.33 to 3.80 . Overall, current administrative heads had the positive attitude to the principals performance in servicing school effectiveness including students acquisition, teachers instruction, administration, or community relations. In general, these results showed most administrative heads had the positive attitude to the principals performance in servicing school effectiveness. Besides, they thought 'community relations' performed perfectly in school effectiveness.

The product moment correlation examined the results of questionnaire and analysed the administrative heads' awareness of principals' conflict management in school effectiveness. The results were shown in Table 4.

Table 4 Correlation Analysis Between Conflict Management and School Effectiveness

\begin{tabular}{|c|c|c|c|c|c|c|}
\hline & \multicolumn{6}{|c|}{ Conflict Management } \\
\hline & & Competition & Cooperation & Compliance & Escape & Compromising \\
\hline \multirow{5}{*}{ 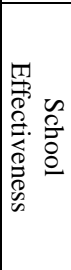 } & $\begin{array}{c}\text { Students' } \\
\text { Acquisition }\end{array}$ & -.00 & $.22^{* * *}$ & -.08 & $-.14^{* *}$ & $.17^{* *}$ \\
\hline & $\begin{array}{l}\text { Teachers' } \\
\text { Instruction }\end{array}$ & -.08 & $.31^{* * *}$ & -.07 & $-.19^{* *}$ & $.28^{* *}$ \\
\hline & Administration & $-.23^{* *}$ & $.44^{* * *}$ & $-.12^{* *}$ & $-.28^{* * *}$ & $.35^{* *}$ \\
\hline & $\begin{array}{c}\text { Community } \\
\text { Relations }\end{array}$ & $-.16^{* * *}$ & $.33^{* * *}$ & -.09 & $-.20^{* *}$ & $.25^{* *}$ \\
\hline & Total & $-.16^{* *}$ & $.41^{* *}$ & $-.11^{*}$ & $-.26^{* * *}$ & $.33^{* *}$ \\
\hline
\end{tabular}

As Table 4, the correlation analysis between conflict management and school effectiveness reached the standard (.01). To analysis escape of conflict management, its correlated measure was .01 and numerical was a negative number. So, it had negative correlation with school effectiveness. Using escape to handle conflicts had made administrative heads decrease the feeling of school effectiveness. To analysis of cooperation and compromising, its correlated measure reached .01 .

Therefore, these two variables had positive correlation. It showed if the principals used cooperation and compromising to handle conflicts, it would increase the administrative heads' feeling of school effectiveness. In order to understand whether 
if the school effectiveness was predictable to each dimensionality of conflict management, we set conflict management as a predictor variable and set school effectiveness as a criterion variable to conduct a statistic analysis via multiple regression analysis as Table 5 showed.

Table5 Multiple Regression Analysis of Conflict Management to School Effectiveness

\begin{tabular}{|c|c|c|c|c|}
\hline & $\begin{array}{l}\text { Multiple Correlation } \\
\text { Coefficient }(\mathrm{R})\end{array}$ & \multicolumn{2}{|c|}{$\begin{array}{c}\text { Coefficient of } \\
\text { Determination }\left(\mathrm{R}^{2)}\right.\end{array}$} & $\begin{array}{c}\text { Increment } \\
\left(\triangle R^{2}\right)\end{array}$ \\
\hline Cooperation & .412 & \multicolumn{2}{|r|}{.170} & .170 \\
\hline Escape & .424 & \multicolumn{2}{|r|}{.180} & .010 \\
\hline Compromising & .438 & \multicolumn{2}{|r|}{.192} & .012 \\
\hline & F test & $\Delta \mathrm{F}$ & B & $\beta$ \\
\hline Intercept & & & 2.707 & \\
\hline Cooperation & $102.90^{* * *}$ & $102.90 * * *$ & .196 & .265 \\
\hline Escape & $55.10^{* * *}$ & $6.24 *$ & -.102 & -.136 \\
\hline Compromising & $39.80^{* * * *}$ & $7.73 * *$ & .133 & .148 \\
\hline
\end{tabular}

As shown in Table 5, there were three significant predictable variables in these five variables. The orders of variances in conflict management were cooperation, escape, and compromising. In these three predictable variables, the multiple correlation coefficient was .44 and its coefficient of determination was .19. Thus, these three variables, we could know the variance of "school effectiveness" reached 19.2\%. In regression mode of three independent variables, the variable cooperation had the biggest variance. Its variance of school effectiveness reached $17 \%$ and its $\mathrm{F}$ test in regression model was $39.8(\mathrm{p}<.001)$. According to Table 5, the best standard regression equation as followed;

$$
\begin{aligned}
\text { School Effectiveness }= & 0.265 \times \text { Cooperation }-0.136 \times \text { Escape } \\
& +0.148 \times \text { Compromising }
\end{aligned}
$$

Regarding the standardized regression coefficient, except for escape, cooperation, compromising had positive influence to school effectiveness. It means the respondents recognized that when the principals met school conflicts, most principals actively chose cooperation and compromising as the way to solve the conflicts. Then, the respondents felt school effectiveness was better.

\section{Conclusions}

\subsection{Using cooperation and compromising methods can successfully increase school effectiveness.}

In five dimensions of conflict management variables, combining three dimensions cooperation, escape, and compromising to explain is finest. In another word, when conflict happens, the senior vocational principals need to be careful with using the conflict management of cooperation, escape, and compromising. While the principal chooses cooperation and compromising as an event to respond the conflict in campus, it brings the positive influence of school effectiveness. Additionally, it is the best to choose the way of 'cooperation' to increase the school effectiveness.

\subsection{The most preferred conflict management chosen by the principals are cooperation and compromising methods.}

The administrative heads knew that when the principals encountered the conflict, they always adopted cooperation and compromising. In addition, the heads thought that it was more acceptable if the principals chose the ways of listening to the colleagues, communicating with the colleagues, and letting the colleagues attend the events to solve the conflicts. As the results of this study, when current senior vocational principals met the conflicts, the competition and compliance were more unacceptable, but cooperation was.

\subsection{It is efficient to predict school effectiveness in the three dimensions of the conflict management of cooperation, escape, and compliance.}

In the five dimensions of conflict management variables, it was obvious to predict school effectiveness in using three dimensions of cooperation, escape, and compliance. Besides, to combine cooperation, escape, compliance to produce the result of predicting is to improve the school effectiveness. It is suitable to be chosen the strategies of cooperation and compliance by principals while the conflict occurred.

\section{References}

[1] Hoy, W. K., \& Miskel, C. G. (2005). Educational administration: Theory, research, and practice. (7th ed.). New York: McGraw-Hill.

[2] Jehn, K. A. (1995). A multi-method examination of the benefits and detriments of intragroup conflict. Administrative Science Quarterly, 40, 256-282.

[3] Kantek, F., \& Gezer, N. (2009). Conflict in schools: Student nurses' conflict management styles. Nurse Education Today, 29(1), 100-107.

[4] Kaushal, R., \& Kwantes, C. T. (2006). The role of culture and personality in choice of conflict management strategy. International Journal of Intercultural Relations, 30, 579-603.

[5] Laugaa, D., Rascle, N., \& Bruchon-Schweitzer, M. (2008). Stress and burnout among French elementary school teachers: A transactional approach. European Review of Applied Psychology, 58(4), 241-251.

[6] Liu, S. (2006). School effectiveness research in China. Unpublished Doctoral Dissertation, Louisiana State University and Agricultural \& Mechanical College, Louisiana.

[7] Newell, R. J., \& Van-Ryzin, M. J. (2007). Growing hope as a determinant of school effectiveness. Phi Delta Kappan, 88(6), 465-471.

[8] Pelled, L. H. (1996). Demographic diversity, conflict, and work group outcomes: An intervening process theory. Organization Science, 7, 615631.

[9] Pondy, L. R. (1967). Organizational conflict: Concepts and models. Administrative Science Quarterly, 12(2), 296-320.

[10] Rahim, M. A. (2010). Managing conflict in organizations. (4th ed.). NJ: Transaction Publishers.

[11] Robbins, S. P. (2001). Essentials of organizational behavior. Englewood Cliffs, NJ: Prentice-Hall.

[12] Thomas, K. (1992). Conflict and negotiation processes in organizations. Handbook of Organizational Psychology, 3, 668.

[13] Torrance, E. P. (1957). Group decision making and disagreement. Social Forces, 35, 314-318.

[14] Townsend, T. (1997). What makes schools effective? A comparison between school communities in Australia and USA. School Effectiveness and School Improvement, 8(3), 311-326.

[15] United Nations Educational Scientific and Cultural Organization (2011). EFA global monitoring report 2011. Retrieved June, 28, 2011, from http://unesdoc.unesco.org/images/0019/001907/190743C.pdf. 